\title{
Vitamin D Deficiency and Acute Lower Respiratory Tract Infection in Toddlers
}

\author{
Mandal A' , Sahi PK²
}

${ }^{1}$ Dr. Anirban Mandal, Department of Paediatrics, Sitaram Bhartia Institute of Science and Research, New Delhi, India. ${ }^{2} \mathrm{Dr}$. Puneet Kaur Sahi, Department of Paediatrics, Kalawati Saran Children's Hospital, New Delhi, India.

\section{Address for correspondence:}

Dr. Anirban Mandal

E-mail: anirban.nrs@gmail.com

\section{How to cite}

Mandal A, Sahi PK. Vitamin D Deficiency and Acute Lower Respiratory Tract Infection in Toddlers. J Nepal Paediatr Soc 2016;36(3):319.

doi: http://dx.doi.org/10.3126/jnps.v36i3.16183

This work is licensed under a Creative Commons Attribution 3.0 License.
Dear editor,

We read with much interest the article Narang, et al ${ }^{1}$ published in the recent issue of your journal and have the following comments to offer:

First:The abstract mentions the objective of the study as "identifying an effective nutritional agent that reduces the need for antibiotics, duration of pneumonia and length of hospitalization" but in the main text it is mentioned as "to determine association of vitamin $\mathrm{D}$ deficiency in children between 2 months to 5 years of age as a risk factor for acute lower respiratory tract infection (ALRTI)". Nevertheless, the study doesn't involve 'testing' any "nutritional agent" in ALRTI.

Second: The authors tried to assess the risk factors of ALRTI by comparing the prevalence of risk factors in cases and controls. But, the very premise of such a comparison is that the two groups (cases and controls) are similar in characteristics other than those assessed. Though the authors have mentioned that "Controls were not matched with cases" but they could have at least presented the baseline demographic (age, sex, etc.) and anthropometric data of these two groups to see whether they were comparable or not.

Third: No exclusion criteria are mentioned. So, it makes one wonder whether patients with recurrent pneumonia and other systemic illnesses were also included in the cases. This is important as the data from this 'special group' of children cannot be extrapolated to general population.

Fourth:The authors did not mention the criteria/ definition used for the following variables: vitamin D deficiency/ sufficient Vitamin D, socio-economic status, wheatish skin color.

Fifth: The conclusion mentions that "there was no association of vitamin $\mathrm{D}$ deficiency with severity of pneumonia" but no such analysis between severity of pneumonia and vitamin $\mathrm{D}$ deficiency was done in the paper. Similarly the data leading to the conclusion that "level of vitamin $\mathrm{D}$ deficiency was inversely related to duration of sunlight exposure in both cases and controls" is also not clear. 


\section{References}

1. Narang GS, Arora S, Kukreja S, Shifali. Association of Vitamin D Deficiency with Acute Lower Respiratory
Infection in Toddlers. J Nepal PaediatrSoc 2016;36(1):14-18.http://www.nepjol.info/index.php/ JNPS/article/viewFile/13982/12857

\section{Response by the authors}

Response by the Editor in Chief: Thank you for the review, we apologise for the inattention by editors and peer reviewers regarding the above and assure you that we shall try our best not to accept such blunders in the future issues. 